\title{
Memórias de uma neta
}

Luana Chnaiderman de Almeida

Resumo: Opresente texto, gentilmente cedido por Luana Chnaiderman à Cadernos de Literatura em Tradução, foi apresentado durante a abertura da Jornada Internacional: Literatura Russa em Tradução, realizada na Faculdade de Filosofia, Letras e Ciências Humanas da USP em 7 de abril de 2016, e dedicada ao grande pioneiro das traducões russas no Brasil, Boris Schnaiderman (1917-2016).

\section{Dezembro, 2016}

Quando eu era criança, eu e minha mãe morávamos no mesmo quarteirão em que ficava o apartamento dos meus avós. Na mesma rua. Um pedaço de calçada, algumas centenas de metros nos separavam. Era possível, do quarto da minha mãe, ver a janela do quarto e da sala dos meus avós, e às vezes, para o meu constrangimento e embaraço, minha mãe e vó conversavam das suas janelas, entre gritos e gestos que atravessavam a vila de casinhas antigas e operárias que nos separava. Hoje mal se vê essa vila, escondida atrás de um shopping center. Outras casas foram derrubadas. A rua foi povoada de restaurantes e comércio gourmet que antes não existiam nem no nome. Da janela da nossa sala, dava para ver montanhas distantes, o Pico do Jaraguá, que eu nunca escalei nem subi, e que hoje é imagem na memória, encoberta por prédios. Mas andar por aquela calçada, aquele pedacinho de terra em meio à cidade enorme é para mim lembrar dos passos do meu avô, da casa onde cresci e da casa da minha avó.

A casa da minha avó era esse lugar perto, onde eu ia jogar dominó e conversar com minha avó na língua xadrez que nós duas havíamos inventado. Uma casa de gatos, a Kika e a Gina, e cachorro, a Chiquinha, que fumava cigarros e bebia uísque. Uma casa repleta de livros, quadros, roupas de seda, maquiagens 
indianas e joias africanas, com as quais eu brincava enquanto comia os chocolates que minha vó me dava, escondida da minha mãe.

Eu era criança e meu avô à noite às vezes percorria a calçada e vinha me contar histórias. Contava histórias de objetos que à noite se rebelavam e faziam festas enquanto as pessoas dormiam. Histórias de ursos malabaristas e lugares distantes. Rebeldia da xícara de café ou do bule de chá. Colheres de prata em revolta. No dia seguinte, nas aulas de redação, eu escrevia as histórias que meu avô me contava, fingindo que eram minhas. Ficava um pouco envergonhada quando chegava o meu caderno escolar repleto de marcações entusiasmadas da professora, como eu era imaginativa e escrevia bem! Sabia-me fingidora, enganava a professora, o nove conquistado não era meu, mas do meu avô, mas não revelava o meu segredo a ninguém.

Meu avô andava pelo bairro inteiro. Sempre andou. Eu era criança e me espantava e orgulhava dos passos firmes do meu avô. Saía pelo bairro para pagar suas contas, comprar pão ou biscoitos, manteiga e geleia para o chá da tarde, ia até o xerox fazer cópias dos livros que eu porventura pedia emprestado.

- Vô, empresta esse livro para mim?

- Eu xeroco, pode deixar.

E quando eu chegava à casa dele, lá estava o xerox, a bibliografia anotada na letra desenhada do meu avô.

Vencia ladeiras gigantes, com seus passos rápidos e firmes, e vinha à USP de ônibus. Nunca vi meu avô dirigindo um carro. A Jerusa para cima e para baixo em seu Peugeot vermelho. Meu avô a pé. Tenho uma lembrança guardada, meu avô no ponto de ônibus, a carteirinha de idoso na mão, tomando o ônibus que o levaria para a faculdade. Havia algo ali, tão fora do lugar, e ao mesmo tempo tão dentro.

Andava e andava pelo bairro, do banco à farmácia, ocupado com o cotidiano e suas miudezas e todos o conheciam como professor.

Eu achava bacana aquilo, meu avô era o professor Boris.

Como o porteiro, a caixa do banco, o sapateiro sabiam que meu avô dava aulas? Todos chamavam meu avô de professor. O bairro inteiro. E eu achava, e ainda acho, aquilo lindo.

Quando andávamos juntos pelas calçadas, meu avô sempre se colocava entre mim e os carros. Demorou para eu perceber, tanto o gesto como aquilo que havia no gesto. Uma gentileza cavalheiresca: ao andar pela calçada o homem deve se colocar entre a mulher e o trânsito. Eu me sentia bem: quando eu me colocava do lado errado do passeio, meu avô dava a volta para me proteger dos males da rua. 
Havia uma gentileza própria do meu avô, que não se separava da sua existência. Por favor, obrigado, muito bem. Uma noção profunda de horizontalidade entre as pessoas, que se traduzia no trato com cada um.

Eu ia tomar chá, ou almoçar às terças-feiras com ele, e ele sempre me perguntava: o que você anda lendo com seus alunos?

- Vô, nós estamos lendo os contos do Tchékhov.

(Eu sempre pronunciava e continuo pronunciando errado, acho que chegou um momento em que ele desistiu de me corrigir...)

- Muito bem, muito bem... E eles estão gostando dos contos do Tchékhov?

- Muito vô, se bem que uma aluna ficou revoltada com aquela história em que um cachorro come os filhotinhos do gato. São tristes, né, vô, os contos do Tchékhov?

- É, são terríveis, mas são uma maravilha.

- Sim. São uma maravilha, os alunos estão amando, vô.

- O Tchékhov falava que o conto devia terminar em pianíssimo.

- Eu sei, vô, você já me contou, mas sabe, eu não entendo bem isso, eu acho que um monte de histórias dele têm sim um fim bem marcado e forte.

- Ele falava que os contos devem começar em forte, e terminar em pianíssimo.

- Vô, queria saber mais sobre teoria do conto.

- Eu tenho um artigo...

E na semana seguinte o artigo estava ali, xerocado à minha espera, a caligrafia do meu avô, cada vez mais torta, marcando as referências bibliográficas.

- Vô, me empresta esse livro?

- Eu xeroco para você.

Fazia bem, meu avô. Da adolescente confusa e perdida que eu era, eram poucas as chances de os livros encontrarem seus caminhos de volta à estante da casa do meu avô.

A língua russa que meu avô falava ao telefone, quando conversava com minha tia Berta, sua irmã, era tão legal, quando eu estava na casa dele e o ouvia falar em russo com minha tia-avó. Parecia que a voz alcançava outra tonalidade e força, uma força longínqua que vinha de um lugar muito distante e ali estava meu avô.

- Vô, você iria lá na escola, conversar com meus alunos sobre os contos de Tchékhov? 
- Claro! Com prazer, com prazer.

E meu avô veio, boina e camisa alinhadas, veio à pé e eu fui recebê-lo à porta da escola, toda orgulhosa, apresentando a todos o meu avô.

Os olhos azuis do meu avô.

Os alunos em círculo, meu vô contando da vida do Tchékhov, médico e escritor, tão preocupado com a vida humana, com a dignidade da vida humana.

Vieram as perguntas.

O primeiro conto que lemos, aquele que abre a antologia $A$ dama do cachorrinho e outras histórias chama-se Pamonha. É a história de uma empregada pamonha, que deixa que o patrão a explore até o último centavo, descontando a louça quebrada, o dia resfriado, o bolo comido. Ao final, a babá recebe uma ninharia, muito distante do salário que lhe era devido. Ela se curva ao patrão, e diz: merci.

O patrão se enfurece, diz que estava fazendo um teste, brincando com ela, como alguém pode ser tão pamonha? E tira da sua mesa de trabalho um envelope com o salário inteiro.

Havíamos conversado bastante em sala de aula sobre esse conto.

E um aluno perguntou:

- Por que o conto se chama pamonha? Tem pamonha na Rússia?

Todos riram daquela pergunta tão fora de propósito. Eu mesma, professora, me inquietei com aquela criatura que não parecia saber o que era uma metáfora ou uma figura de linguagem.

Meu avô, já tendo vivido mais de noventa anos, olhou para o garoto.

- Não tem pamonha na Rússia.

Todos riram.

Meu avô continuou, sério:

- Você tem razão. Não é uma boa tradução. Eu vou mudar na próxima edição.

O aluno assentiu, sério. E toda classe e eu olhamos em espanto para aquele professor, aquela autoridade máxima e sábia, que havia conversado e de fato escutado a pergunta de um rapazote de dezessete, entre os muros de uma escola, no bairro.

No dia seguinte meu avô me ligou, perguntando o nome completo do menino, para contar no livro Tradução, ato desmedido, a história da pamonha e dar os créditos devidos ao autor da pergunta. 
- Vô, por que você foi para a guerra?

- Não havia como não ir.

- Como assim, vô, fala mais sobre isso... desenvolve, me conta os detalhes.

- Era o fascismo, Luana. A gente tinha que lutar contra o fascismo. Não havia como não ir.

Uma vez eu era criança chegando à adolescência e ganhei uma gatinha, quis chamá-la de Krieg. Havia algo que eu achava bonito naquela sonoridade alemã, lembrava o grito de guerra do Tarzã, krig ha bandolo, enfim.

- Como ela se chama?, perguntou meu avô.

- Krieg.

- Mas "krieg” quer dizer guerra, em alemão.

- Eu sei, vô, mas eu gosto do nome.

- Mas guerra é uma coisa horrível, não se deve dar um nome assim para um bicho de estimação, é um nome terrível.

Eu me lembro da gata filhote, lembro de tê-la nas minhas mãos, mas não lembro do seu destino, nem se ficou chamando Krieg. Espero que não. Mas eu fazia muita besteira, naquela época, e acho que ainda agora, mas hoje sei melhor dos pesadelos que meu avô tinha com a guerra, como ficava agitado com as lembranças ruins, sei das histórias que contava e tento imaginar aquelas que ele calou.

Eu era criança e ia fazer pesquisa na casa do meu avô. Ele e a Jerusa tinham duas versões da Enciclopédia Britânica. De anos diferentes, uma mais filosófica, outra mais informativa. Eram em espanhol e eu as enfrentava porque o mundo inteiro estava naquelas enciclopédias. E nas estantes do meu avô.

$\mathrm{Na}$ casa do meu avô havia muitos quadros, um deles, uma fotografia em preto e branco, os contrastes estourados, de uma mulher de olhos pretos arregalados olhando fixo para a lente da câmera. $\mathrm{O}$ cabelo muito preto, em coque, separado por risca firme. O lábio marcado por batom quase preto. Ao lado dela, um homem bonito, maxilar quadrado, marcado, olhos grandes e duros, que não acabavam mais. Eu tinha medo daquela mulher, eu era criança e pensava que era uma bruxa russa. E aquele homem misterioso que não sabia quem era, mas sabia que havia se matado.

Depois soube. Eram Lilian Brik e Maiakóvski. Ela, musa dos poetas vanguardistas russos, libertária. Ele fazia cartazes. E fazia poesias para os operários. E eu imaginava aquele casal estranho, o homem careca de macacão de pintor, em cima de uma escada, colando cartazes pelas ruas russas, antes de amar aquela 
mulher de olhos arregalados. Seus retratos na casa do meu avô nunca deixaram de me assombrar.

Eu usava umas camisetas enormes e chamativas, com grandes dizeres em línguas estrangeiras, geralmente o inglês.

Um dia meu avô perguntou:

- O que está escrito na sua camiseta, Luana?

- Eu não sei, vô, está em inglês.

- E como você usa uma camiseta com escritas que você não entende?

- Sei lá, vô, é bonita.

- Mas e se tiver escrito, por exemplo, viva o Maluf?

E eu nunca mais usei nenhuma camisa com dizeres que eu não soubesse traduzir.

Usei outra, no colegial, que me fazia bastante popular, especialmente entre os meninos mais velhos. Uma camiseta branca e justa, com uma frase do Maiakóvski, em português. Andava com elas e as pessoas me paravam. Um dia um menino mais velho me disse que queria até comprá-la. Uma frase famosa atribuída ao Maiakóvski: "Antes morrer de vodca que morrer de tédio".

Fazia muito sucesso, aquela camiseta. Eu achava o máximo.

Uma vez, na quinta série, o professor pediu para que a gente trouxesse um poema para a classe, um poema que a gente gostasse muito. Todos trouxeram Drummond, Vinicius. Manuel Bandeira. Eu, toda contente, cheguei com meu poema preferido, que era Balalaica, do Maiakóvski, que decorei e sei até hoje.

Balalaica

[como um balido abala

a balada do baile

de gala]

[com um balido abala]

abala [com balido]

[a gala do baile]

louca a bala

laika.

O professor olhou o poema que eu havia trazido. Leu, releu, olhou para a minha cara. 
Eu tinha dez anos, e ele me falou para ler o poema para toda a classe.

Eu li.

E o professor falou:

- Agora explica.

Eu fiquei quieta, a classe inteira olhando para mim.

Não tinha a menor ideia do que aquele poema significava.

Não sabia o que era uma balalaica, nem uma balada de um baile. Mas achava lindo o som. E imaginava uma cabra balindo em meio a um baile de gala, coisa mais engraçada. E legal. E quando meu avô falava o poema em russo, a música era parecida.

Mas não sabia, nem soube, explicar o poema.

Saí do tablado um pouco envergonhada de ter trazido um poema que ninguém entendia.

Hoje talvez fosse capaz de fazer uma análise sociológica, sonora, a luta de classes, o instrumento popular em meio ao baile dos ricos, as aliterações e a força aberta do A.

Mas eu prefiro minha imaginação de criança, que gostava da música e achava engraçado uma cabra balindo no meio do baile.

Estávamos na quinta série, e aprendíamos sobre a Guerra Fria e eu tinha avós russos, ateus e comunistas. Do outro lado, avós acreanos. Que espantam meus alunos, que afirmam que o Acre não existe. Nem a Rússia. A União Soviética não mais.

Eu tinha onze anos estávamos em plena Guerra Fria e o professor de história nos perguntou se alguém ali da classe sabia o que era a Sputnik, e eu toda empolgada levantei a mão, ansiosa:

- Eu sei, eu sei! É uma vodca muito boa! Meu vô toma todos os dias um copinho, sempre tem lá em casa, você deixa a vodca no congelador e ela fica leitosa.

A classe inteira riu, inclusive o professor.

Depois a vodca virou cachaças mineiras, que os amigos traziam. Um copinho, de vez em quando, e eu achava meu avô muito russo, quando ele propunha um brinde, virava o copo cheio, aos noventa e nove anos.

Toda minha vida, os professores, ao verem meu nome na chamada:

- Você é parente do Boris Schnaiderman?

- Ele é meu avô. 
E alguma história.

Na graduação, em letras, passei a assinar meus trabalho como Luana Almeida. Achava, tinha certeza, que os professores seriam mais exigentes e teriam mais expectativas, ao saber do meu avô. Hoje, fico muito feliz em estar aqui como neta.

- Vô, eu escrevi um livro de contos e queria te mostrar.

Havia se passado muito tempo, desde o caderno infantil no qual eu copiava ou transcriava, não sei, as histórias do meu avô.

Eu já havia me formado, feito mestrado, casado, separado, encontrado meu amor que hoje me acompanha.

Continuei escrevendo, buscando histórias próprias, mas sempre escondida.

Mas agora eu tinha um livro de contos, escrito e reescrito e achei que podia mostrá-lo ao meu avô.

Quem xerocou desta vez fui eu.

De xerox nas mãos, deixei o livro lá. Era a primeira vez que deixava algo de meu para que ele lesse.

Alguns dias depois, meu avô me liga.

- Luana, eu li seu livro de contos, e gostaria de marcar uma conversa com você. Você pode vir aqui em casa, na quarta feira, às cinco da tarde?

Fiquei sem dormir todos aqueles dias, até o dia marcado.

Eu tinha uma reunião com meu avô.

- Luana, eu li seu livro de contos e fiquei muito confuso. A gente não sabe quando um conto termina e outro começa. Sabe, por mais que a gente tenha uma concepção larga de contos, por mais que a gente saiba que não existe uma forma fechada para aquilo que é conto, muitos dos seus escritos são apreensões de momentos pegos no ar, mas não são contos, eu fiquei muito confuso.

O livro corrigido, verbos e pronomes nos lugares errados.

- Mas tem um conto, um conto seu, que é grande e mostra onde você pode chegar. Este conto irá permanecer e durar por muitos anos. E poderia estar em qualquer antologia de grandes contos.

E eu voltei para casa feliz.

Meu livro estava tão confuso que meu avô nem tinha lido inteiro.

Mas tinha um conto ali que sim.

Que poderia durar e fazer sentido daqui a cinquenta anos.

E que o resto não era bem conto. 
E eu reli, pensei, decidi que o que era apreensão de algum estado de espírito catado no ar poderia talvez continuar assim, mas que eu deveria ter consciência disso. E o que precisava de trabalho, corpo, enredo, personagem e ação, precisava de trabalho. E eu refiz o livro inteiro.

Eu chegava às terças-feiras para almoçar com meu avô. Meio dia. Os horários do meu avô e o relógio que lhe acompanhava os passos. Chegava para encontrá-lo sempre sentado à sua mesa de trabalho, um grande caderno no qual fazia anotações daquilo que lia, a máquina de escrever que lhe acompanhou a vida inteira. A música das teclas da máquina de escrever.

- Vô, é difícil achar tinta para a máquina de escrever?

- Que tinta?! É fita, Luana, é fita...

Sentávamos um pouco no sofá, antes de o almoço ficar pronto.

- E o que você anda lendo com seus alunos?

O almoço ficava pronto e comíamos na cozinha, meu avô alegre e entusiasmado com o tempero do feijão, do franguinho, a boa comida da Cecília e da Maria.

Meu avô animado com os livros do porvir.

Meu avô na cama do hospital no primeiro dia do internamento contando sempre de tudo o que estava por vir.

Que ele precisava escrever. Os livros que ele preparava.

- Vô, você foi amigo do Murilo Mendes?

Sim, li um dos livros de poema dele, fiquei muito impressionado e escrevi para ele. Nos correspondemos, tornamo-nos amigos. Ele tinha uma mulher muito chata.

Rubem Fonseca. Cortázar.

- Vô, conta aquela história do Cortázar?

- Ele era muito atrapalhado, o Cortázar. Veio ao Brasil encontrar a mãe e a irmã, o Mindlin disponibilizou um carro com motorista para levá-los a Campos de Jordão. Ao final da temporada, o Cortázar me liga para dizer que não tinha como pagar o hotel. Ele tinha consigo somente dólares canadenses, e o gerente do hotel não queria aceitar o pagamento em dólares canadenses, ele era muito atrapalhado, o Cortázar, não tinha nenhum senso prático... Um dia ele veio e nós fomos passear pelo centro, tomar um chopp. Todos que passavam olhavam para a gente, viravam o rosto, ficavam olhando. O Cortázar ficou todo contente: "Viu, Boris, como eu sou famoso? Todos aqui me reconhecem, ficam me olhando, sabem bem quem eu sou". 
Então meu avô começava a rir:

- Mas acontece que o Cortázar era uma figura muito estranha, aquele homem muito bonito e gigante, e todos olhavam por causa disso, aquele homem muito alto e estranho, andando pela rua, chamava a atenção e ele todo feliz: "viu Boris, como eu sou conhecido?"

No hospital, nos últimos dias, contava de novo para mim essas histórias.

- Você me deu uma boa ideia, eu preciso escrever um texto sobre minha amizade com o Cortázar, vou escrever, vou escrever.

Meu avô nas mostras de cinema, nas últimas exposições, empolgado com as novas marchinhas de carnaval e com os memes de Whatsapp.

Meu avô apreciando a entrada na Jerusa, na casa, na cozinha, como está bela, os colares, as bolsas, as cores da Jerusa e a alegria do meu avô ao vê-la.

A falta de jeito para o canto, que eu herdei do meu avô. O apreço pelo silêncio e alguma falta de jeito para a conversa jogada fora, também herdados.

O entusiasmo, que é ter um deus dentro de si.

O sol vindo tomar um chá com o operário.

Explicando que gente é para brilhar.

Uma lição que meu avô nunca esqueceu.

Dezembro de 2016 